\title{
Parental Engagement in IB Schools: How Is It Underpinned by School Leaders? A Cross-National Comparative Analysis.
}

\author{
Elisabeth Neiada \\ Department of Education, University of Bath
}

\begin{abstract}
Parental engagement in children's' school experience plays a vital role in supporting student learning and securing positive school-family relations. Existing literature recognizes different levels and forms of parental involvement in schools, determined by cultural context, school leadership models, parenting practices and types of schools. In this paper, I attempt to examine the relationship between parental engagement and school leadership in a comparative context of international schooling.

The study will be an ethnography, to gain insight to the insiders' views, experiences and perspectives of parents and school leaders. A mixed methods approach will be employed, using contextual large-scale questionnaires, interviews and observations with parents and school leaders. This study is original, as it explores parental engagement and leadership in private IB schools. These schools are currently understudied, as are families of higher socio-economic status that constitute the schools' parent community. Furthermore, the study focuses on Middle School ages (11-16 years old) where there is a gap in research. Literature shows a sudden drop of parental engagement in Middle School, while there is scientific evidence that Middle School students need equal or more parental support than Primary School students (Hayden \& Thompson, 2013).

It is hoped that this research will contribute to a deeper understanding of international schools and international education, two driving forces of educational change on a national and global scale.
\end{abstract}

Keywords: educational leadership; international schools; parenting; relationships; student learning. 